
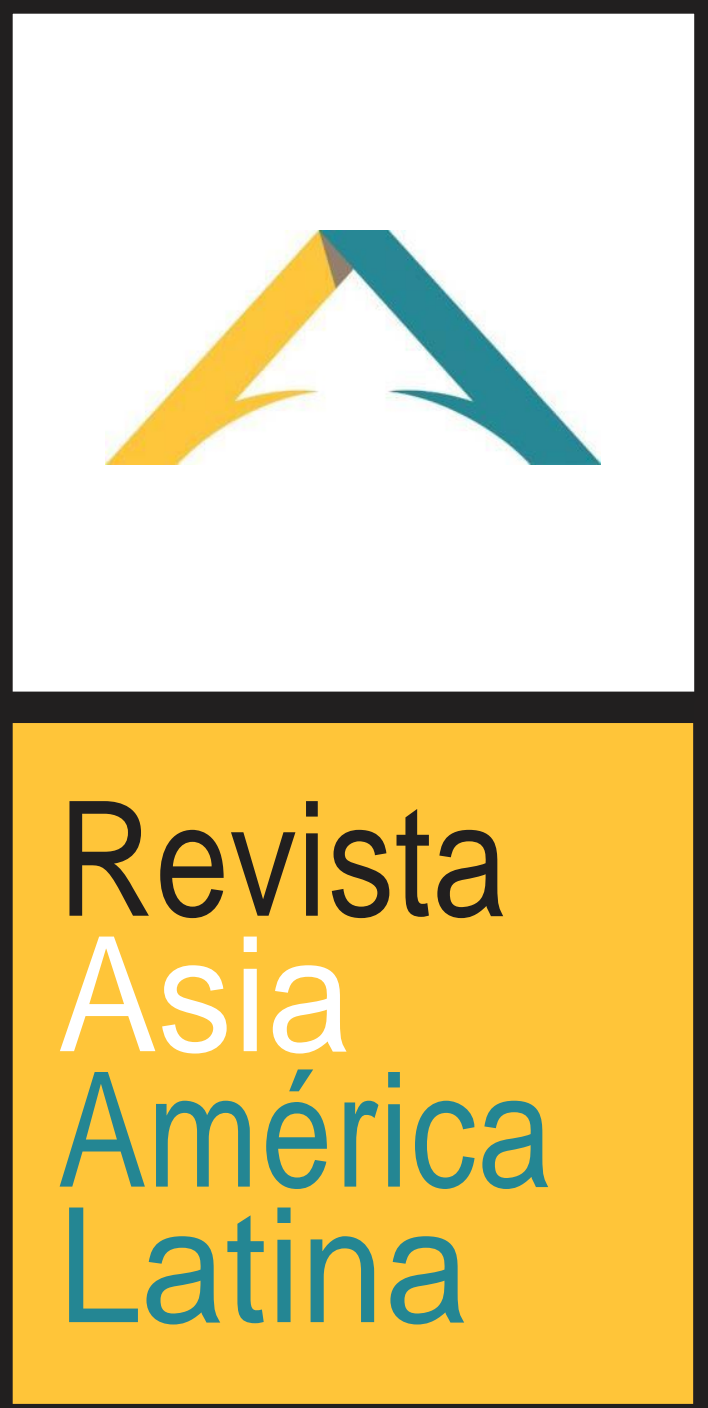

ISSN 2524-9347

Grupo de Estudios sobre Asia y América Latina Instituto de Estudios de América Latina y el Caribe Universidad de Buenos Aires

EU

DE BA 


\section{EL DESAFÍO DE LOS CAPITALISMO ASIÁTICOS}

THE CHALLENGE OF ASIAN CAPITALISM

\section{Diego García}

Universidad de Buenos Aires

diegar04@gmail.com

La pandemia de COVID-19 vuelve a mostrar logros y desafíos de los capitalismos asiáticos. Como en otras oportunidades, la escala de sus problemas y de sus soluciones desafía la imaginación política en América Latina y en todo el mundo. ¿Quién hubiera dicho hace unos años que, ante una crisis de este tipo, no íbamos buscar respuestas en el Reino Unido o Francia, sino en China y Corea del Sur?

En este contexto de cuarentena mundial, el pensamiento político en América Latina tomó contacto con soluciones diferentes a las que encuentra en experiencias más familiares. En comercio electrónico, industria bancaria, regulación de internet, financiamiento de infraestructura o propiedad de la tierra - por nombrar solo algunos ejemplos-, Asia pone en práctica ideas diferentes. Empecemos con una de las cuestiones que recibió más atención en las discusiones recientes: el control digital. Muchos análisis expresan preocupación por la posibilidad de que nuestra libertad sea limitada por el uso gubernamental de tecnologías de información. Muchos otros denuncian que eso ya está pasando. No se puede tener una idea precisa sobre esto si no advertimos, sobre todo reduccionismo y sobre toda exotización, que los regímenes políticos en Asia no son todos iguales. Taiwán es una democracia multipartidaria desde 1996. Singapur es un país con elecciones, gobernado por el mismo partido desde su fundación en 1965, con un parlamento con representación de un partido de oposición. Corea del Sur comenzó su transición hacia la democracia multipartidaria en la década del 90 y hoy 10 partidos diferentes integran su Asamblea Nacional. Japón es una monarquía constitucional en la que el primer ministro es elegido por un parlamento, al estilo anglosajón. China tiene un gobierno de partido único, con autoridades regionales designadas por el gobierno central y con sistemas de consultas populares para decisiones locales.

Estar atentos a diferencias y matices nos permite, por un lado, notar que en el este de Asia también las democracias con reglas similares a las de América Latina tienen políticas de seguimiento digital. Por el otro, advertir que ni siquiera en China hay alguien que tenga control total sobre la sociedad. Porque, sin dejar de ser cierto que el gobierno chino tiene reglas diferentes a las de las democracias, es fantasía que allá la población acepte 
cualquier trato del gobierno. Entre China y América Latina hay muchas diferencias, desde luego. Pero ninguna de ellas tapa que también en China, como en todas partes, hay discusiones, mentiras, luchas internas, secretos y resistencias. Una de las tareas más difíciles de pensar Asia contemporánea desde América Latina es dar en el clavo con la medida de las diferencias y las similitudes. Pero sin una calibración rigurosa de diferencias y matices corremos el riesgo de quedar abrazados a imágenes gruesamente inexactas.

Una segunda cuestión a precisar es la relación íntima entre la revolución capitalista en Asia y eso a lo que en América Latina se le dice "neoliberalismo". Porque la oferta de fuerza de trabajo barata durante los años 80 y 90 fue un pilar del despegue asiático. Esa oferta de trabajo barato fue posible por el surgimiento de cadenas de producción globales que permitieron a miles de millones de trabajadores asiáticos participar en un mercado global de trabajo. Sin embargo, su incorporación al mercado de trabajo global expuso a los trabajadores de las economías industriales y de su periferia semiindustrializada a una competencia extremadamente áspera. Porque mientras los trabajadores de América Latina buscábamos salvar el poder de compra que habíamos conseguido desde 1945, los nuevos trabajadores asiáticos ofrecían su fuerza de trabajo por muchísimo menos. Esta competencia es una de las razones que explican el estancamiento, cuando no la caída, del poder de compra de los salarios de los trabajadores América Latina, Estados Unidos y Europa.

Para peor, los problemas que esta nueva división internacional del trabajo nos trajo a los trabajadores de América Latina se montaron sobre un problema previo: el repliegue del Estado de Bienestar que empezó a gestarse después de la crisis del petróleo de 1973. A partir de ese momento, los Estados de las economías industriales y su periferia empezaron a recortar los beneficios que recibíamos sus ciudadanos como consecuencia de la cuadruplicación del precio del petróleo entre octubre de 1973 y marzo de 1974. Porque ese salto histórico en el precio del petróleo volvió a las industrias de Europa y Estados Unidos más costosas que lo que sus sociedades podían soportar. Para hacerlas más competitivas, la primera medida exitosa fue aliviar la carga del Estado sobre las empresas, reduciendo impuestos. Pero la reducción de impuestos no era posible sin reducción del gasto. A partir de entonces, los ciudadanos de los países industrializados y de su periferia recibimos cada vez menos. El largo declive del Estado de Bienestar tiene relación directa con la brutal redistribución del ingreso entre las economías industriales y las economías exportadoras de petróleo. Para cuando tuvimos que afrontar los rigores de la competencia asiática, los ciudadanos de América Latina - pero también los de Estados Unidos y Europa- contábamos con Estados que proveían menos servicios que en 1973.

Lo que se llama en América Latina "neoliberalismo" no se puede 
entender sin estos dos impactos: el auge asiático de las décadas del 80 y del 90 y el levantamiento de los países petroleros en la década del 70. La competencia asiática catalizó los mecanismos con los que se afrontó el aumento del precio del petróleo: optimización de la eficiencia, ajuste sistemático de los costos, competencia económica sin cuartel. Desde esta perspectiva, "neoliberalismo" es el nombre que agrupa las estrategias de salvataje económico de Estados Unidos y Europa, cuando los países de Medio Oriente y del este de Asia reclamaron una mejor parte de la torta. El análisis de estos dos impactos echa luz sobre un aspecto, aunque crucial, poco presente en las discusiones latinoamericanas. Que la mejora de condiciones de vida que los latinoamericanos conocimos durante el siglo Xx también se explica por la fortaleza del capitalismo de Estados Unidos y Europa sobre los países pobres de Medio Oriente, la India y el este de Asia.

De esta lectura ya se desprenden tres incertidumbres. La primera, sobre la relación entre concentración de la riqueza y aumento de la desigualdad. Porque la redistribución global del ingreso es paralela a la concentración del ingreso y al aumento de la desigualdad en todos los países de América Latina y del mundo. Pero una comprensión cabal de este problema no puede pasar por alto que la concentración de la riqueza no fue correlativa, en Occidente y en Oriente, de los mismos procesos. En Estados Unidos, desde 1973 a la fecha creció el número de superricos paralelamente al número de pobres. Pero en China, el aumento de la desigualdad fue de la mano de la reducción de la pobreza, en escalas igualmente asombrosas. La segunda incertidumbre es por la relación entre crítica del imperialismo y crítica del capitalismo. Porque las experiencias de, por ejemplo, Vietnam y China, dan indicios para pensar que lo que limitaba el desarrollo de los países del tercer mundo no era el exceso de capitalismo, sino su ausencia. Aunque se requerirían más estudios para llegar a conclusiones certeras sobre esta hipótesis. La tercera incertidumbre es sobre un tercer impacto, el impacto fantasma - para citar a Jacques Derrida-: la desaparición del movimiento comunista internacional. La disolución de la Unión Soviética tiene un rol incierto en esta historia. Y esto por tres razones. Primero, porque no hay dudas de que, por diferentes mecanismos, la disolución de la Unión Soviética debilitó el movimiento de trabajadores en muchos lugares del mundo ¿ $\mathrm{O}$ es al revés: el agotamiento de ese movimiento al menos, tal como se había estructurado globalmente durante el siglo XXanunciaba el agotamiento del proyecto de la Unión Soviética? Segundo, porque la disolución de la URSS permitió a trabajadores de muchos países del tercer mundo mejorar sus ingresos ofreciendo su fuerza de trabajo en un mercado laboral globalizado. Tercero, porque no es claro cuál habría sido la trayectoria del socialismo en la Unión Soviética, viendo cuál fue su destino en China.

Ahora bien, si se piensa el capitalismo, no puede quedar sin pensar el Estado. En esto también los modelos asiáticos ofrecen alternativas a las 
concepciones más presentes en América Latina. Pensemos dos figuras representativas: el Estado como obstáculo de la iniciativa privada y el Estado como una fuente de justicia distributiva. Las dos están fundadas en la misma idea: entre Estado y mercado hay tensión, cuando no antinomia. Las discusiones sobre el este de Asia, por el contrario, ofrecen maneras de pensar Estado y el mercado más en sintonía que en contradicción. Porque hay consenso sobre que los logros en los países del este Asia no hubieran sido posibles sin la colaboración entre empresas y Estado. El 5G chino y la industria automotriz japonesa; el cine coreano y la inteligencia artificial taiwanesa; la reducción de la pobreza en China y la expansión financiera de Hong Kong. Ninguno habría sido posible sin la colaboración estrechísima de Estado y empresas. Pero no hace falta viajar a Asia ni ser líder en innovación tecnológica para entender esto. Que Estado y mercado, liderazgo político y libertad de comercio, inversión estratégica y competencia, libertad individual y esplendor nacional son cosas compatibles entre sí es un dato elemental de la historia, desde el siglo XVII al XXI, desde el Reino Unido a Singapur.

Todo esto dirige la reflexión a la última cuestión, verdaderamente cardinal: la desconfianza como fundamento de la política en Europa y América. Porque desconfianza del mercado y del Estado se basan en una dicotomía anterior entre desconfianza del individuo y desconfianza de la comunidad. Las cuatro, hijas siamesas de la filosofía moderna, parten del mismo principio de inorganicidad de los procesos, de autonomía de los ámbitos, las cosas o las personas. La filosofía moderna expresó estas ideas con claridad meridiana. En términos epistemológicos, ahí está la duda metódica de Descartes. En términos políticos, ahí está el pacto de Hobbes. En Corea, en China, en Japón, por el contrario, nadie creería que la sociedad se funda en un contrato entre individuos, ni que los individuos preexisten a la sociedad. Desde esta perspectiva, la sociedad no está unida por la voluntad, el cálculo o el interés, sino por un lazo moral. Deberes y derechos no están definidos por un contrato acordado sino por una moral compartida. Vistas las cosas de esta manera, Estado y mercado son diferentes manifestaciones del mismo vínculo primario: aquel que asegura que la armonía entre individuo y comunidad es posible.

Esta manera de pensar relaciones orgánicas entre Estado y mercado, entre individuo y comunidad, abre la ventana para un corolario final, aunque metafísico, relevante para la interpretación del capitalismo asiático y su impacto en el debate latinoamericano. Hegel, uno de los últimos pensadores de la modernidad, integró la desconfianza moderna en una lectura general de la historia, que permitió pensar esa desconfianza, no como un antígeno dentro del cuerpo social, sino como una chispa vital inicial. Inspirado por Hegel, Marx hizo algo similar e imaginó una teleología de la liberación en la desconfianza del capitalismo como un momento preliminar que iba a generar las condiciones para un momento superior de emancipación comunista. ¿Cómo podemos 
interpretar esas esperanzas emancipadoras, a la luz de lo mucho que en el presente está motorizado por el capitalismo asiático, a la luz de toda la potencia desplegada por China en su paso al capitalismo, finalmente, a la luz de la pobreza en América Latina? ¿Acaso el capitalismo chino es emancipatorio? ¿Es que el capitalismo asiático es un antiimperialismo? ¿Es el germen de un imperialismo diferente? ¿Lo que está pasando en Asia está más allá de una dialéctica de la emancipación? ¿La pobreza mundial es una refutación total y final del marxismo? Del hecho de que el capitalismo no haya sido superado por un modo de producción moralmente superior no se puede concluir que no vaya a ser superado en el futuro. Pero en la espera podemos preguntarnos si, tal vez, la organicidad del capitalismo no será exterior, sino interior. Es decir, si el capitalismo es orgánico con algo que viene después de él y lo supera, o, tal vez, con algo que está antes y de donde él surge. Quizás -no seríamos los primeros en decir algo sobre esto- el capitalismo no sea algo exterior, que pasa fuera de nosotros, sino la expresión económica de una estructura emocional, la forma que nuestro deseo le da a la sociedad. 

